\title{
The Effect of Virtual Reality Rehabilitation on Balance in Patients with Parkinson's Disease: A Systematic Review and Meta-Analysis
}

\author{
Wenjing Wang (D), Sharon Sui-lam Wong (D) and Frank Ho-yin Lai * (D) \\ Department of Rehabilitation Sciences, The Hong Kong Polytechnic University, Hung Hom, Hong Kong; \\ wenjing.wang@connect.polyu.hk (W.W.); sharon-sl.wong@polyu.edu.hk (S.S.-1.W.) \\ * Correspondence: frank.hy.lai@polyu.edu.hk
}

check for updates

Citation: Wang, W.; Wong, S.S.-1.; Lai, F.H.-y. The Effect of Virtual Reality Rehabilitation on Balance in Patients with Parkinson's Disease: A Systematic Review and Meta-Analysis. Electronics 2021, 10, 1003. https://doi.org/10.3390/ electronics10091003

Academic Editor: Antonino Naro and Rocco Salvatore Calabrò

Received: 20 March 2021

Accepted: 20 April 2021

Published: 22 April 2021

Publisher's Note: MDPI stays neutral with regard to jurisdictional claims in published maps and institutional affiliations.

Copyright: (c) 2021 by the authors. Licensee MDPI, Basel, Switzerland. This article is an open access article distributed under the terms and conditions of the Creative Commons Attribution (CC BY) license (https:// creativecommons.org/licenses/by/ $4.0 /)$.

\begin{abstract}
As a popular method, virtual reality (VR) is still controversial in its effect on the balance function of patients with Parkinson's disease. This systematic review aims to discuss such effects of VR and to compare it with that resulting from traditional therapies. A comprehensive search was conducted for randomized controlled trials published from 2000 to 2020 through the following databases: PubMed, Web of Science, CINAHL, Embase, Cochrane Library. Fifteen articles were included for the systematic review. An evaluation on their methodological qualities was performed using the PEDro scale, followed by an assessment of their risk of biases in accordance with the Cochrane Handbook for Systematic Reviews of Interventions for quality assessment. In terms of dynamic balance, the BBS score of the VR group was significantly improved when compared with the control group $(\mathrm{SMD}=0.52,95 \% \mathrm{CI}=0.31-0.73)$. However, no significant difference was observed between the two groups on TUG (SMD $=-0.26 ; 95 \% \mathrm{CI}=-0.62-0.1 ; p=0.16$ ). Besides, the VR group also showed better results in improving patients' static balance, balance confidence, and quality of life. A funnel plot was created to investigate the effects of each study included in the meta-analysis in order to identify any existing publication bias. This systematic review shows that the application of VR leads to more significant improvement in the balance of patients with Parkinson's disease than having them perform traditional exercises. It can be used as an auxiliary method of rehabilitation.
\end{abstract}

Keywords: virtual reality; balance; Parkinson's disease

\section{Introduction}

Parkinson's disease (PD) is a neurodegenerative disease mainly leading to movement disorders, such as static tremor, bradykinesia, rigidity, and postural instability. These symptoms will worsen over time, not only causing difficulties in balance, but also causing patients to lose their confidence in maintaining it, increasing the risk of falls and decreasing their measures of quality of life [1]. The most significant feature of PD is the decrease in dopamine content in the brain, which is closely related to the severity of the loss of dopaminergic neurons in the substantia nigra compact area, leading to the loss of gait autonomy and balance [2]. Therefore, dopamine replacement therapy is an important treatment for PD. However, it cannot prevent continued deterioration of body function [3], and balance and gait-related symptoms are resistant to drugs [4]. Therefore, physical therapy is a necessary auxiliary method for the treatment of PD. It can improve balance function [5,6] and enable patients to perform their activities of daily living independently, thereby improving their quality of life.

It is becoming popular to use VR to treat patients with PD. By definition, VR is a computer-generated virtual environment with which people can interact in a natural way and produce a sense of immersion in the corresponding real environment [7]. It has three key characteristics: immersion, presence, and interactivity [8]. Immersion refers to the degree to which VR can provide a full range of sensory stimuli that are not originated from 
the physical environment, as well as a high degree of matching between users' actions and the corresponding information generated by the system [9]. Immersion can affect the patients' experience of VR. By providing multiple visual, auditory, and tactile sensory cues, it affects the patients' sense of presence, and through the psychological satisfaction obtained from indulging in appropriate challenges during the interaction, patients can be immersed in the world created by VR. The provision of user control, appropriate challenges, and the enablement of feelings of success are the key elements to immerse patients in the VR system [10]. There are three types of VR, namely non-immersive, semiimmersive, and fully immersive. Non-immersive VR equipment mainly includes mice, joysticks, and high-resolution monitors. It requires the lowest cost of all the virtual reality systems, and brings to its customers the lowest sense of immersion and interaction. Fully immersive VR equipment mainly includes gloves, voice commands and head-mounted displays, which are very expensive but can bring about the highest sense of immersion and interaction [11]. VR can promote the movement and cognitive processes of its participants, thereby increasing their chances of regaining lost motion abilities [12]. It can also be used to carry out personalized repetitive training of balance function and obtain realtime visual feedback [13], in order to promote the motor learning, maintenance, and transfer of its users [14]. Patients can be trained using commercially available equipment (such as Nintendo Wii or XBOX) or custom-made VR systems. Through the provision of training within a challenging and stimulating environment, VR can also effectively maintain patients' interests and motivation to adopt it in practice [15]. Besides, these devices can be used at home or be catered for patients in lower socioeconomic conditions to help increase their adherence to rehabilitation [16]. Therefore, VR can have long-term effects on these patients, as it could have prevented or slowed down the progression of their physical dysfunctions.

Some systematic reviews have identified the effects of VR on PD patients in the past, but the conclusions drawn were of opposite views [17,18]. Moreover, they only used a few outcome measures to evaluate the improvement in patients' balance functions. Therefore, whether VR has any beneficial impact on the balance of PD patients has yet to be determined. In recent years, new studies have evaluated the pros and cons of both VR and traditional therapies on their treatment to PD. As such, the purpose of this systematic review is to determine the effect of VR on the balance functions of patients with PD when compared with traditional therapies by assessing the results obtained from the measurement of different types of balance.

\section{Materials and Methods}

\subsection{Literature Search}

This systematic review was conducted following the Preferred Reporting Items for Systematic Reviews and Meta-Analyses (PRISMA) guidelines (Supplementary Materials File S1). VR has been an emerging technology with a variety of potential benefits in many aspects of rehabilitation assessment, treatment, and research since 2000 [7]. Through its capacity, which allows for the creation and control of dynamic 3-dimensional, ecologically valid stimulus environments within which behavioral responding can be recorded and measured, VR offers clinical assessments and rehabilitation options that are not otherwise available with traditional methods [19]. Solid evidence through ongoing research that had studied the effectiveness of evolving VR technologies within the context of rehabilitation has been accumulating since then [20]. In view of this, we retrieved references from PubMed, Web of Science, CINAHL, Embase, Cochrane Library, PEDro from 2000 to 2020. The main search terms include Parkinson's disease ("PD", "Parkinson disease", "Parkinsonism", "Paralysis agitans", or "Parkinsonian"), virtual reality ("VR", "Virtual reality exposure therapy", "Virtual reality immersion therapy", "exergam*”, "X-BOX", "Kinect", or "Wii"), and randomized controlled trials ("controlled clinical trial", "randomized", or "randomly"). 


\subsection{Inclusion Criteria}

Our research question was based on the Population Intervention Comparison Outcomes and Study (PICOS) principle. Studies that met the following criteria were eligible: (1) Participants diagnosed with PD; (2) Randomized controlled trials; (3) The experimental group used VR training while the control group received traditional treatment. NonEnglish research and reviews and conference abstracts were excluded. The titles and abstracts were screened to select the references deemed qualified. Then, full texts were extracted to fully evaluate whether they had indeed met the above inclusion criteria.

\subsection{Outcome Measures}

According to the study by Schoneburg [21], balance function is related to four posture systems: static balance, dynamic balance, reactive posture adjustment, and expected posture adjustment. These systems may affect the balance of PD patients and increase the risk of falls. Therefore, the main results collected were related to static balance, dynamic balance, and posture control, including (1) Static balance. The One-Leg Stance (OLS) Test (Single-Leg Stance Test or Unipedal Stance Test), the Limits of Stability (LOS), and the Sensory Organization Test (SOT) were used to evaluate static balance ability. (2) Dynamic balance. The Berg balance scale (BBS) and the Timed Up and Go (TUG) Test were used to measure the patients' dynamic balance ability. (3) Balance confidence. The Falls Efficacy Scale (FES) and the Specific Activity Balance Scale (ABC) were used to measure the patients' confidence when performing activities that may affect their balances and cause them to fall. (4) Quality of life. Quality of life was evaluated using the 39-Item Parkinson's Disease Questionnaire (PDQ-39).

\subsection{Data Extraction and Quality Assessment}

Two reviewers searched for articles and screened them according to the established search strategy. After determining the studies to be included in the literature, the reviewers conducted data extraction and quality evaluation. During the evaluation process, if uncertainties were encountered while reviewing certain articles, they would be revaluated by another reviewer. The following data were extracted: (1) Article information; (2) Main characteristics of the sample (sample size, composition, diagnosis, disease stage); (3) Experimental content (intervention, dosage, measurement); (4) The main results. The qualities of the literature were evaluated by the PEDro scale. Scores in the range of 0-3 were of low quality, 4-6 were of medium quality, and 7-10 were of high quality. Using the bias domains as set out in the Cochrane Handbook for Systematic Reviews of Interventions [22] for quality assessment, all included studies were being evaluated in order to determine their risk of biases. The studies were rated as having "low risk of bias", "high risk of bias", or an "unclear risk of bias".

\subsection{Statistical Analysis}

As the resulting indexes involved in this article were continuous scalars, we selected the standardized mean difference (SMD) and a 95\% confidence interval (CI) as the effect size. The heterogeneity of the experiment was evaluated using a forest plot and the I2 statistic. When I 2 was less than $50 \%$, the heterogeneity was considered acceptable, and so the fixed effects model was selected. Otherwise, the random-effects model would be chosen. Among the outcome variables, $p<0.05$ was considered statistically significant. Review Manager 5.4 under the Cochrane Collaboration protocols was used to perform a meta-analysis.

\section{Results}

\subsection{Study Selection and Quality Assessment}

Through the database searches, 408 related papers were found. After removing duplicated documents and screening the remaining papers, 15 articles were included as depicted in Figure 1. The risk of biases was shown in Figures 2 and 3. In summary, one 
article had a low risk of bias, 13 articles had an unclear risk of bias, and one article had a high risk of bias.

The quality ratings of these studies ranged from 4 to 8 (Table 1). Among them, 12 experiments scored 6 or above on the PEDro scale, so their qualities were rated as good (Supplementary Materials File S2). No participants were blinded to the interventions and only one study involved therapists who were blinded. Six studies concealed the allocation of all their participants.

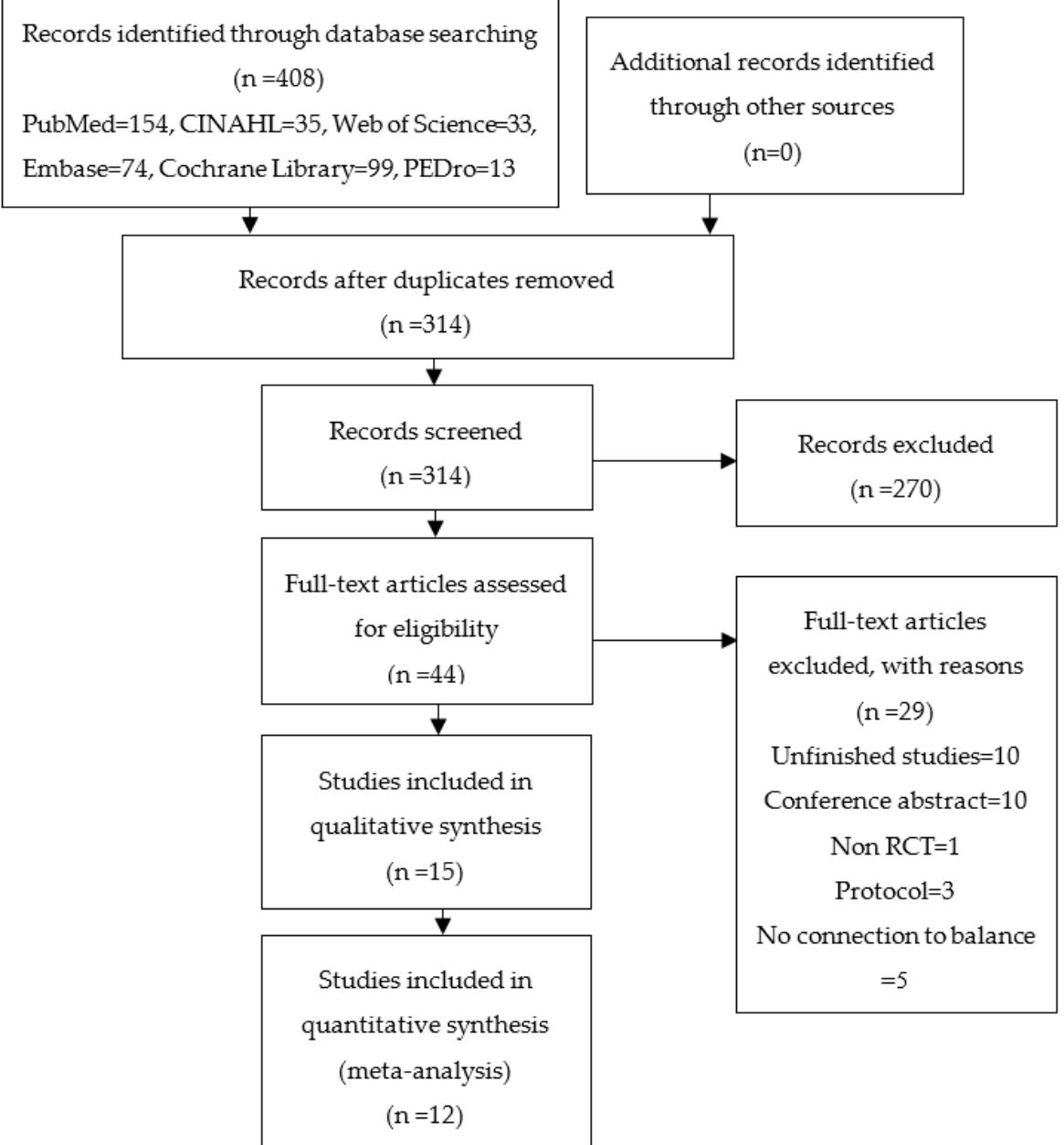

Figure 1. Preferred Reporting Items for Systematic Reviews and Meta Analyses (PRISMA) Flow Diagram.

Random sequence generation (selection bias)

Allocation concealment (selection bias)

Blinding of outcome assessment (detection bias)

Incomplete outcome data (attrition bias)

Selective reporting (reporting bias)

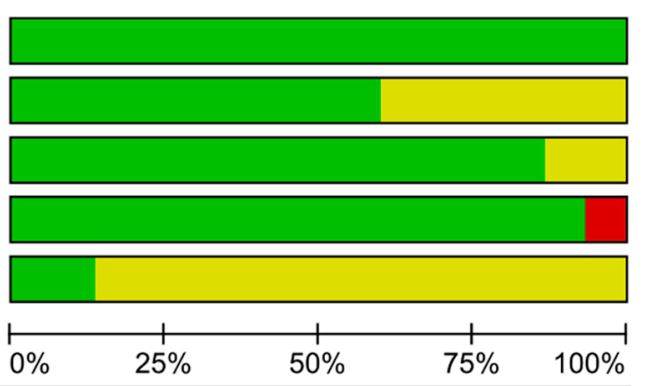

Low risk of bias

Unclear risk of bias

High risk of bias

Figure 2. Risk of bias graph: review authors' judgements about each risk of bias item presented as percentages across all included studies. 
Table 1. Characteristics of the included studies.

\begin{tabular}{|c|c|c|c|}
\hline Study & Outcomes & Findings & PEDro \\
\hline $\begin{array}{l}\text { Yang } \\
2016\end{array}$ & $\begin{array}{c}\text { BBS } \\
\text { TUG } \\
\text { PDQ-39 }\end{array}$ & No significant differences were found in BBS, TUG, PDQ-39 & 7 \\
\hline $\begin{array}{l}\text { Tollár } \\
2019\end{array}$ & $\begin{array}{l}\text { PDQ-39 } \\
\text { BBS }\end{array}$ & $\begin{array}{l}\text { VR group showed a greater improvement in BBS compared with the } \\
\text { control group }\end{array}$ & 6 \\
\hline $\begin{array}{l}\text { Heuvel } \\
2014\end{array}$ & $\begin{array}{c}\text { BBS } \\
\text { SLS } \\
\text { FES } \\
\text { PDQ-39 }\end{array}$ & No significant differences were found in FRT, BBS, SLS, FES, PDQ-39 & 8 \\
\hline $\begin{array}{l}\text { Shih } \\
2016\end{array}$ & $\begin{array}{l}\text { LOS OLS } \\
\text { BBS TUG }\end{array}$ & Significant improvement in LOS, OLS, BBS, TUG & 6 \\
\hline $\begin{array}{l}\text { Santos } \\
2019\end{array}$ & $\begin{array}{c}\text { BBS } \\
\text { TUG } \\
\text { PDQ-39 }\end{array}$ & Significant improvement in BBS, TUG, PDQ-39 & 6 \\
\hline $\begin{array}{l}\text { Ribas } \\
2017\end{array}$ & $\begin{array}{c}\text { BBS } \\
\text { PDQ-39 }\end{array}$ & $\begin{array}{l}\text { Significant improvement in BBS, but this benefit was not sustained in } \\
\text { the long-term }\end{array}$ & 7 \\
\hline $\begin{array}{l}\text { Pompeu } \\
2012\end{array}$ & $\begin{array}{l}\text { BBS } \\
\text { UST }\end{array}$ & No significant differences were found in BBS, UST & 5 \\
\hline $\begin{array}{l}\text { Pazzaglia } \\
2020\end{array}$ & BBS & $\begin{array}{l}\text { VR group showed a greater improvement in BBS compared with the } \\
\text { control group }\end{array}$ & 5 \\
\hline $\begin{array}{l}\text { Liao. } \\
2015 a\end{array}$ & $\begin{array}{c}\text { TUG } \\
\text { LOS } \\
\text { SOT } \\
\text { FES } \\
\text { PDQ-39 }\end{array}$ & Significant improvement in TUG, LOS, SOT, FES, and PDQ-39 & 7 \\
\hline $\begin{array}{c}\text { Lee } \\
2015\end{array}$ & BBS & Significant improvement in BBS & 4 \\
\hline $\begin{array}{l}\text { Gandolfi } \\
2017\end{array}$ & $\begin{array}{l}\mathrm{BBS} \\
\mathrm{ABC}\end{array}$ & Significant improvement in $\mathrm{BBS}$ and $\mathrm{ABC}$ & 6 \\
\hline $\begin{array}{l}\text { Feng } \\
2019\end{array}$ & $\begin{array}{l}\text { BBS } \\
\text { TUG }\end{array}$ & Significant improvement in BBS, TUG & 6 \\
\hline $\begin{array}{l}\text { Pedreira } \\
2013\end{array}$ & PDQ-39 & $\begin{array}{l}\text { VR group showed greater improvement in the PDQ-39 than the control } \\
\text { group }\end{array}$ & 4 \\
\hline $\begin{array}{l}\text { Liao } \\
2015 b\end{array}$ & SOT & No significant difference was found in SOT between the two groups & 7 \\
\hline $\begin{array}{l}\text { Yen } \\
2011\end{array}$ & SOT & VR group showed greater improvement in SOT-6 than control group & 8 \\
\hline
\end{tabular}

Note. BBS, Berg Balance Scale; TUG, Timed Up and Go Test; PDQ-39, 39-Item Parkinson's Disease Questionnaire; SLS, Single Leg Stance; LOS, Limits of Stability; OLS, One-Leg Stance; UST, Unipedal Stance Test; FES, Falls Efficacy Scale; ABC, Activities Balance Confidence scale; SOT, Sensory Organization Test. 


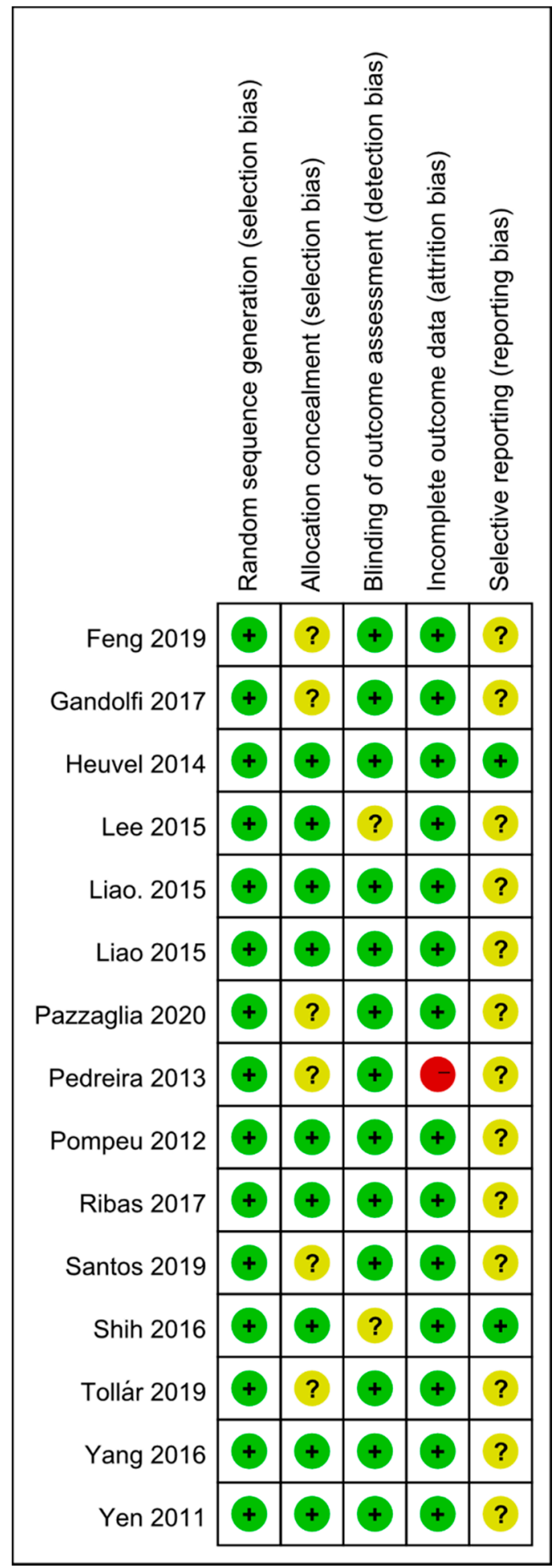

Figure 3. Risk of bias summary: review authors' judgements about each risk of bias item for each included study.

\subsection{Main Characteristics}

While Table 1 showed the outcomes, main findings, and the PEDro scores of the included studies, their experimental designs were described in Table 2. Fifteen studies [23-37] were published from 2011 to 2020, which included 569 subjects. Gandolfi, Geroin [36] and Tollár, Nagy [26] had the highest number of participants in their studies, which were 76 and 74 respectively. Except for these two as well as the studies by Santos, Machado [28], 
Pazzaglia, Imbimbo [32], and Yen, Lin [23], all other studies involved less than 40 participants. The ages of the subjects were between 50 and 85 years old, of which 344 were male. Thirteen studies [23-31,33,34,36,37] used a modified Hoehn and Yahr scale to assess the stages of severity of the patients' PD. Most of the subjects were in stages 1 to 3 , and only one study included patients in stage 4 [37]. Two studies did not report these data [32,35].

All experimental groups adopted non-immersive VR interventions. Nine compared VR with conventional training $[24,25,27,29-32,36,37]$, four compared VR with conventional training and no treatment $[23,26,33,34]$, and two compared VR with traditional training and VR combined with traditional training [28,35]. Patients in the experimental groups completed their training related to balance through following the instructions on the computer monitors or projection screens. Eight studies used the Nintendo Wii Fit system [28-31,33-36]. The rest of the research used other equipment, including an X-box 360 core system [26], Kinect sensor, balance board [23,25,27], or custom-made VR systems [24,32,37]. The number of embedded VR games that were introduced to the participants varied from study to study, ranging from two [24] to ten [36]. Five studies had the games played in blocks $[24,26,28,31,32]$, such that the participants were allowed to take breaks in between each game. These breaks ranged from 1 minute each $[28,31,32]$ to 5 min each $[24,26]$.

The duration of the interventions varied from 5 to 12 weeks, and their frequency of treatments ranged from 2 to 5 times a week. The intensity of the treatments ranged from $30 \mathrm{~min}$ to $60 \mathrm{~min}$, ten of which included warm-up sessions prior to the start of the actual VR or conventional training $[23,24,26-28,30-32,36,37]$, and four out of which also had cool-down sessions afterwards $[26,27,32,37]$. The reported warm-up durations ranged from $5 \mathrm{~min}[26,37]$ to $10 \mathrm{~min}[23,24,27,28,30,31]$. On top of the initial 10-min warm-up, one study also involved an extra $20 \mathrm{~min}$ of global exercises that were focused on the limbs, the trunk and the neck before the actual intervention began [30]. Two other studies that included warm-up sessions did not specify their durations [32,36]. There was one study which involved a 5-min cool-down exercise towards the end of each intervention session [26], while two other studies reported that a 10-min cool-down was given to participants at the end of each session $[27,37]$. The remaining study did not report the duration of its cool-down session [32].

In terms of participant selection, all studies had conformed to the exclusion of potential subjects who would have encountered great difficulties following the proposed activities due to various forms of physiological impairments, including orthopedic injuries, neurological dysfunctions, or other chronic diseases. Four studies had additionally considered the exclusion of PD patients with depression [24,26,30,36], since depression is known to be an accompanying clinical condition in some individuals inflicted by PD, which may further affect their performances and lead to biased results. One study excluded participants with symptoms that are highly similar to those of PD [32], including secondary Parkinsonism and Parkinson-plus, so as to ensure that the recruited subjects were exclusively affected by PD. Two studies had accounted for the possible influence of past learning effects, and excluded participants who have had prior experiences playing with Nintendo Wii $[29,30]$.

In assigning participants to different study arms, all studies had adopted the random allocation approach. Three studies randomly assigned their subjects to different groups through the use of computerized methods that produced computer-generated random numbers $[24,29,31]$. Eight studies achieved randomization through the drawing of objects by an independent assessor, including sealed envelopes [25,27,29,33,34], colored ribbons [26], and drawing of names or assignment cards [23,30]. The other four studies did not provide details on their randomization methods $[28,32,35,37]$. 
Table 2. Characteristics of the included studies.

\begin{tabular}{|c|c|c|c|c|c|}
\hline \multirow[b]{2}{*}{ Study } & \multicolumn{2}{|l|}{ Sample } & \multicolumn{2}{|c|}{ Intervention } & \multirow[b]{2}{*}{ Dosage } \\
\hline & $\begin{array}{c}\text { Diagnosis } \\
\text { Hoehn and Yahr }\end{array}$ & $\begin{array}{l}\text { Size } \\
M / F\end{array}$ & Experimental Group & Control Group & \\
\hline $\begin{array}{l}\text { Yang } \\
2016\end{array}$ & $\begin{array}{l}\text { IPD } \\
2-3\end{array}$ & $\begin{array}{c}23 \\
14 / 9\end{array}$ & VR balance training $(\mathrm{n}=11)$ & $\begin{array}{l}\text { Conventional home balance } \\
\text { training }(\mathrm{n}=12)\end{array}$ & $\begin{array}{c}50 \mathrm{~min} / \mathrm{d} \\
2 \mathrm{~d} / \mathrm{w} \\
6 \mathrm{w}\end{array}$ \\
\hline $\begin{array}{l}\text { Tollár } \\
2019\end{array}$ & $\begin{array}{l}\text { PD } \\
2-3\end{array}$ & $\begin{array}{c}74 \\
36 / 38\end{array}$ & $\begin{array}{l}\text { Exergaming } \\
\quad(\mathrm{n}=25)\end{array}$ & $\begin{array}{c}\text { Stationary cycling }(C Y C)(n=25) \\
\text { Waitlist } \\
(\mathrm{n}=24)\end{array}$ & $\begin{array}{c}60 \mathrm{~min} / \mathrm{d} 5 \mathrm{~d} / \mathrm{w} \\
5 \mathrm{w}\end{array}$ \\
\hline $\begin{array}{l}\text { Heuvel } \\
2014\end{array}$ & $\begin{array}{l}\text { IPD } \\
2-3\end{array}$ & $\begin{array}{c}33 \\
20 / 13\end{array}$ & $\begin{array}{c}\text { Augmented visual feedback } \\
\text { (VFT) } \\
(\mathrm{n}=17)\end{array}$ & $\begin{array}{l}\text { Conventional training } \\
\qquad(\mathrm{n}=14)\end{array}$ & $\begin{array}{c}60 \mathrm{~min} / \mathrm{d} \\
2 \mathrm{~d} / \mathrm{w} \\
5 \mathrm{w}\end{array}$ \\
\hline $\begin{array}{l}\text { Shih } \\
2016\end{array}$ & $\begin{array}{l}\text { IPD } \\
1-3\end{array}$ & $\begin{array}{c}20 \\
16 / 4\end{array}$ & Exergaming group $(\mathrm{n}=10)$ & $\begin{array}{l}\text { Balance training group } \\
\qquad(\mathrm{n}=10)\end{array}$ & $\begin{array}{c}50 \mathrm{~min} / \mathrm{d} \\
2 \mathrm{~d} / \mathrm{w} \\
8 \mathrm{w}\end{array}$ \\
\hline $\begin{array}{l}\text { Santos } \\
2019\end{array}$ & $\begin{array}{l}\text { PD } \\
1-3\end{array}$ & $\begin{array}{l}45 \\
31 / 14\end{array}$ & $\begin{array}{c}\text { NW } \\
(\mathrm{n}=15) \\
\mathrm{NW}+\mathrm{CE} \\
(\mathrm{n}=15)\end{array}$ & $\begin{array}{l}\text { Conventional exercise (CE) } \\
\qquad(\mathrm{n}=15)\end{array}$ & $\begin{array}{c}50 \mathrm{~min} / \mathrm{d} \\
2 \mathrm{~d} / \mathrm{w} \\
8 \mathrm{w}\end{array}$ \\
\hline $\begin{array}{l}\text { Ribas } \\
2017\end{array}$ & $\begin{array}{l}\text { PD } \\
1-3\end{array}$ & $\begin{array}{c}20 \\
8 / 12\end{array}$ & $\begin{array}{l}\text { Exergaming } \\
\text { Wii fit games } \\
\quad(\mathrm{n}=10)\end{array}$ & $\begin{array}{l}\text { Conventional exercise } \\
\qquad(\mathrm{n}=10)\end{array}$ & $\begin{array}{c}30 \mathrm{~m} / \mathrm{d} \\
2 \mathrm{~d} / \mathrm{w} \\
12 \mathrm{w}\end{array}$ \\
\hline $\begin{array}{l}\text { Pompeu } \\
2012\end{array}$ & $\begin{array}{l}\text { IPD } \\
1-2\end{array}$ & $\begin{array}{c}32 \\
17 / 15\end{array}$ & $\begin{array}{l}\text { Wii-based motor training } \\
\qquad(\mathrm{n}=16)\end{array}$ & $\begin{array}{l}\text { Traditional balance exercise } \\
\qquad(\mathrm{n}=16)\end{array}$ & $\begin{array}{c}60 \mathrm{~min} / \mathrm{d} \\
2 \mathrm{~d} / \mathrm{w} \\
7 \mathrm{w}\end{array}$ \\
\hline $\begin{array}{l}\text { Pazzaglia } \\
2020\end{array}$ & $\begin{array}{l}\mathrm{PD} \\
\mathrm{NA}\end{array}$ & $\begin{array}{c}51 \\
35 / 16\end{array}$ & $\begin{array}{l}\text { VR rehabilitation } \\
\qquad(\mathrm{n}=25)\end{array}$ & $\begin{array}{l}\text { Conventional program } \\
\qquad(\mathrm{n}=26)\end{array}$ & $\begin{array}{c}40 \mathrm{~min} / \mathrm{d} \\
3 \mathrm{~d} / \mathrm{w} \\
6 \mathrm{w}\end{array}$ \\
\hline $\begin{array}{l}\text { Liao } \\
2015 a\end{array}$ & $\begin{array}{l}\text { IPD } \\
1-3\end{array}$ & $\begin{array}{l}36 \\
17 / 19\end{array}$ & $\begin{array}{l}\text { VR-based Wii Fit exercise } \\
\qquad(\mathrm{n}=12)\end{array}$ & $\begin{array}{l}\text { Traditional exercise } \\
(\mathrm{n}=12) \\
\text { Control group } \\
(\mathrm{n}=12)\end{array}$ & $\begin{array}{c}1 \mathrm{~h} / \mathrm{d} \\
2 \mathrm{~d} / \mathrm{w} \\
6 \mathrm{w}\end{array}$ \\
\hline $\begin{array}{c}\text { Lee } \\
2015\end{array}$ & $\begin{array}{l}\text { PD } \\
\text { NA }\end{array}$ & $\begin{array}{c}20 \\
10 / 10\end{array}$ & $\begin{array}{l}\text { VR + NDT and functional } \\
\text { electrical stimulation } \\
\qquad(\mathrm{n}=10)\end{array}$ & $\begin{array}{l}\text { NDT and functional electrical } \\
\text { stimulation } \\
(\mathrm{n}=10)\end{array}$ & $\begin{array}{c}45 \mathrm{~min} / \mathrm{d} \\
5 \mathrm{~d} / \mathrm{w} \\
6 \mathrm{w}\end{array}$ \\
\hline $\begin{array}{l}\text { Gandolfi } \\
2017\end{array}$ & $\begin{array}{c}\mathrm{PD} \\
2.5-3\end{array}$ & $\begin{array}{c}76 \\
51 / 25\end{array}$ & $\begin{array}{l}\text { VR telerehabilitation } \\
\qquad(\mathrm{n}=38)\end{array}$ & $\begin{array}{l}\text { Sensory integration balance } \\
\text { training }(\mathrm{n}=38)\end{array}$ & $\begin{array}{c}50 \mathrm{~min} / \mathrm{d}, 3 \mathrm{~d} / \mathrm{w} \\
7 \mathrm{w}\end{array}$ \\
\hline $\begin{array}{l}\text { Feng } \\
2019\end{array}$ & $\begin{array}{c}\text { PD } \\
2.5-4\end{array}$ & $\begin{array}{c}30 \\
17 / 13\end{array}$ & $\begin{array}{l}\text { VR training } \\
\qquad(\mathrm{n}=14)\end{array}$ & Conventional therapy $(\mathrm{n}=14)$ & $\begin{array}{c}45 \mathrm{~min} / \mathrm{d} \\
5 \mathrm{~d} / \mathrm{w} \\
12 \mathrm{w}\end{array}$ \\
\hline $\begin{array}{l}\text { Pedreira } \\
2013\end{array}$ & $\begin{array}{l}\text { PD } \\
1-3\end{array}$ & $\begin{array}{c}31 \\
22 / 9\end{array}$ & $\begin{array}{l}\text { Nintendo Wii virtual games } \\
\qquad(\mathrm{n}=16)\end{array}$ & $\begin{array}{l}\text { Traditional exercise } \\
\qquad(\mathrm{n}=15)\end{array}$ & $\begin{array}{c}40 \mathrm{~min} / \mathrm{d} \\
3 \mathrm{~d} / \mathrm{w} \\
4 \mathrm{w}\end{array}$ \\
\hline $\begin{array}{l}\text { Liao } \\
\text { 2015b }\end{array}$ & $\begin{array}{l}\text { IPD } \\
1-3\end{array}$ & $\begin{array}{l}36 \\
17 / 19\end{array}$ & $\begin{array}{l}\text { VR-based Wii Fit exercise } \\
\qquad(\mathrm{n}=12)\end{array}$ & $\begin{array}{c}\text { Traditional exercise } \\
(\mathrm{n}=12) \\
\text { Control group } \\
(\mathrm{n}=12)\end{array}$ & $\begin{array}{c}60 \mathrm{~min} / \mathrm{d} \\
2 \mathrm{~d} / \mathrm{w} \\
6 \mathrm{w}\end{array}$ \\
\hline $\begin{array}{l}\text { Yen } \\
2011\end{array}$ & $\begin{array}{l}\text { IPD } \\
2-3\end{array}$ & $\begin{array}{c}42 \\
33 / 9\end{array}$ & $\begin{array}{l}\text { VR balance training } \\
\qquad(\mathrm{n}=14)\end{array}$ & $\begin{array}{l}\text { Conventional balance training } \\
(\mathrm{n}=14) \\
\text { Control group } \\
(\mathrm{n}=14)\end{array}$ & $\begin{array}{c}30 \mathrm{~min} / \mathrm{d} \\
2 \mathrm{~d} / \mathrm{w} \\
6 \mathrm{w}\end{array}$ \\
\hline
\end{tabular}


With the exception of two studies [30,35], all other studies had conducted their assessments and/or interventions only when they coincided with the participants' "on" periods after they had taken their medications beforehand. In particular, four studies clearly reported that they carried out both their assessments and interventions 1 to $2 \mathrm{~h}$ after the participants had taken their drugs $[23,26,28,31]$. The delays were essential since they accounted for the fact that the effects of drug intake were not immediate and that it required time for medications to attain their maximal effect.

Of the 15 studies, 12 had appointed qualified physical therapists as trainers during the intervention periods $[23-26,28-30,32-34,36,37]$. One study additionally required the presence of a caregiver during the exercises [36], since the interventions were delivered remotely at the patients' own homes. The appointment of physical therapists in carrying out the interventions helped increase the safety levels of the programs as they were able to guide the participants through the provision of appropriate instructions as well as guard the participants against potential falls.

Of all experimental groups, twelve had used commercially available VR-based game systems [23,25-31,33-36], including Nintendo Wii and XBOX, which are widely popular as home-based video games and are known for their qualities to simulate real environments that could easily engage users' interactivity and enjoyment. Nonetheless, all game-based systems being reviewed in this study had the potential of increasing participants' motivation to complete the games at hand through the posing of challenging goals, the showcasing of their progress in the form of points scored, and the possible promotion from one level to another. They were capable of providing participants with timely visual, perceptual, and auditory feedback, which had a positive influence on the participants' final performances. Among the three that had adopted custom-made VR balance training programs, one reported that it had better served the specific purposes of the study as well as the needs of the recruited participants through the customization of scenarios that mimic everyday living tasks, and also through the development of more adjustable game difficulty levels [24].

Of the control groups, all studies except five [23,26,33-35] had similar training objectives as their experimental counterparts. Four of these studies adopted conventional exercises from either regional guidelines on physical therapy exercises for PD patients $[25,32,37]$ or from following the models developed by previous studies [29]. Six studies had general training protocols that were similar or the same as the experimental groups in terms of the focus of the exercises involved $[24,27,28,30,31,36]$. The five studies whose control groups did not share similar training objectives with the experimental groups involved minimal to no amounts of exercise [23,26,33-35]. Two of them consisted of fall prevention education [33,34], one involved neurodevelopment treatment and functional electrical stimulation [35], and two involved untrained control groups [23,26]. The inclusions of untrained control groups were useful in facilitating the elimination of results caused by physical degenerations due to time effect.

Except for two studies [26,36], sample sizes were generally considered small and was therefore the key limitation in most studies, which affected the strength of interpretation as well as the generalizability of their results. On the other hand, studies with large sample sizes were able to produce outcome measures that were backed by stronger data, which subsequently lead to conclusions that were of greater significance.

\subsection{Results of Main Outcomes}

\subsubsection{Static Balance}

Three studies $[25,27,30]$ evaluated the results from patients' OLS Tests. Van den Heuvel, Kwakkel [25] found that there was no significant difference between the two groups $(p>0.0017)$, but an insignificant trend was in favor of VR. Pompeu, Mendes [30] found that the patients were able to stand on one leg with a lengthened amount of time in both groups, and that the effect was still maintained during the follow-up period $(p<0.05)$. Shih, Wang [27] found that when patients used the less affected leg to support their bodies, 
the recorded one-leg standing time while they had their eyes closed was significantly improved from $3.35 \mathrm{~s}$ to $6.1 \mathrm{~s}$.

Two studies $[27,34]$ evaluated the improvement of LOS. Both studies found that VR can significantly improve patients' directional control. Shih, Wang [27] found that VR can improve the performance of patients with their eyes closed. The reaction time increased from $0.96 \mathrm{~s}$ to $0.74 \mathrm{~s}$, while the endpoint excursion increased from $75.2 \%$ to $84 \%$, and the directional control increased from $75.7 \%$ to $78 \%$. Liao, Yang [34] found that the effects of VR on movement velocity, maximum excursion, and directional control were more significant after training and during the follow-up period.

Three studies [23,33,34] evaluated the results of the SOT. Liao, Yang [34] found that the results were significantly better than those in the control group $(p<0.001$ after training, $p<0.001$ during follow-up). Another study showed that the vestibular integration ability and visual integration ability of the VR group had been more significantly improved [33]. Yen, Lin [23] showed that the improvement in balance in the VR group was more significant $(p<0.001)$, but then this improvement could not be sustained upon follow-up. When patients had difficulties relying on the information received via visual and somatosensory input, VR can significantly improve their sensory integration in order to help them maintain their postural stability.

\subsubsection{Dynamic Balance}

The impact of VR on the BBS was tested by combining the post-intervention data from 11 studies [24-30,32,35-37]. Figure 4 reported the BBS results of 378 patients. There was no heterogeneity among the studies (I2 $=17 \% ; p=0.28$ ), and a fixed-effects model was applied. Overall, our meta-analysis showed that the balance of patients in the VR group had significantly improved, and that the BBS score had increased after the interventions $(\mathrm{SMD}=0.52,95 \% \mathrm{CI}=0.31-0.73)$.

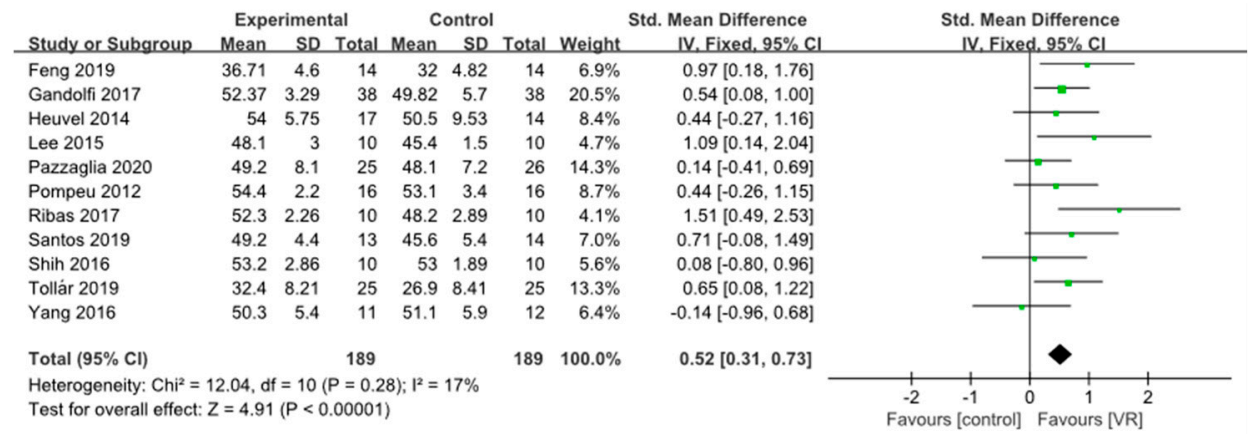

Figure 4. Meta-analysis results for Berg balance scale (BBS).

Five studies [24,27,28,34,37] evaluated the effect of VR on the TUG test, which included 122 patients (Figure 5). There was no heterogeneity among the studies ( $2=12 \% ; p=0.33$ ), and a fixed-effects model was used. Meta-analysis showed that there was no statistically significant difference between the two groups $(\mathrm{SMD}=-0.26 ; 95 \% \mathrm{CI}=-0.62-0.1 ; p=0.16$ ).

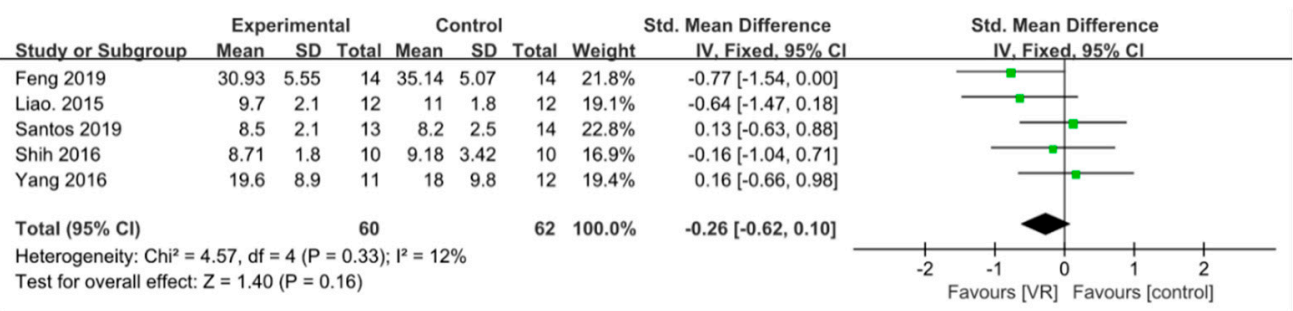

Figure 5. Meta-analysis results for Timed Up and Go (TUG). 


\subsubsection{Confidence in Balance}

Three studies $[25,34,36]$ reported the impact of VR on the patients' balance confidences. Gandolfi and Geroin [36] used the ABC and found that patients in both groups had significant improvements in their self-confidences after the interventions, and that this effect had lasted and was still captured during the follow-up period. Liao, Yang [34] and van den Heuvel, Kwakkel [25] used the FES to assess the confidence levels of their participants. Liao. et al. found that patients in the VR group showed more significant improvements $(p<0.001$ after the intervention, $p=0.001$ during the follow-up period). On the contrary, Heuvel et al. did not observe any statistically significant difference between the two groups $(p=0.42)$, but the results showed an insignificant trend in favor of VR.

\subsubsection{Quality of Life}

Seven studies [24-26,28,29,31,34] evaluated the PDQ-39 scores of patients with PD. Most studies found that VR significantly improved the quality of life of those patients. Pedreira and Prazeres [31] found that the overall quality of life score of patients in the VR group had improved by more than $10 \%(p<0.05)$. Only two studies showed that the two groups had no significant improvement in their quality of life scores $[25,29]$.

\subsection{Publication Bias}

A funnel plot was produced to identify whether there was any publication bias (Figure 6). The plot showed that the effects of each test were relatively evenly distributed on both sides. However, the existence of publication bias cannot be ruled out since most of the included studies had a small sample size.

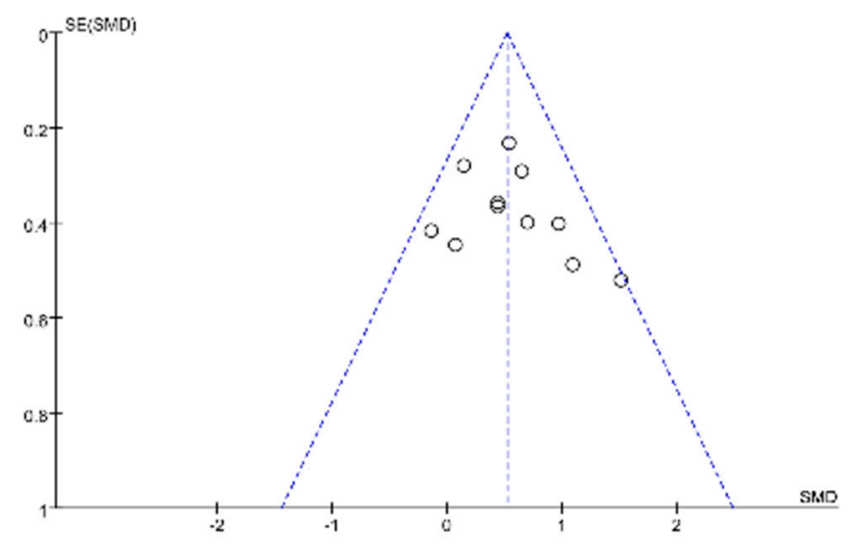

Figure 6. Funnel plot.

\section{Discussion}

This systematic review included 15 studies. The results showed that in terms of static balance, BBS, and balance confidence, VR can, to a certain extent, achieve better effects than traditional training. The results of TUG suggested that there was no significant difference between the two methods. Therefore, it is believed that VR can improve the balance function of PD patients, and is to a certain extent more effective than traditional training.

VR can improve the patients' motivation and enjoyment, improve their compliance to rehabilitation, and reduce the amounts of fatigue experienced [10,29], all of which are achievable through its generation of real-time feedback involving the audiovisual and tactile senses, creating an immersive virtual environment for the patients to explore and move about. A review reported that patients' performances could be improved by increasing their immersion, and that the enjoyment derived from engaging in VR had in turn increased their willingness to participate in more rehabilitation plans [38]. In this review, all selected trials had used non-immersive VR as their experimental intervention, which is the least immersive form of VR comprising custom-made ones as well as commercially available ones such as Nintendo Wii and XBOX, which to a certain extent may have compromised 
the patients' immersive experiences during the training as well as affected their subsequent rehabilitation effect. Nonetheless, it still managed to show that patients' compliance was higher when VR training was adopted instead of traditional training. In six studies, all recruited patients had stayed on throughout the entire study duration and completed all the experimental processes $[26,29,30,32,35,37]$. In other studies, the number of people who completed the entire study was higher in the VR group than that in the control group. Except for one participant from the VR group who preferred traditional training [24] and one who did not believe in the effect of VR [31], only 12 other individuals belonging to the VR group had withdrawn from the studies due to personal issues or other health problems. In comparison, a total of 28 people had withdrawn from the control groups, of which 9 withdrew due to a lack of motivation or a loss of interest $[23,31,33]$.

Future studies are recommended to investigate the effects resulting from participants' engagement in other types of immersive VR game systems, including fully immersive versions where subjects are equipped with head-mounted displays or VR glasses that are capable of producing stereoscopic 3D effects within simulated environments, and compare these performances against those resulting from non-immersive VR training. One of the fully immersive VR systems that has been receiving increasing interest is the Cave Automatic Virtual Environment (CAVE), which is a room-sized cube in which 3D visualization of virtual environments (VEs) occurs thanks to the combination of four stereoscopic projectors, three rear-projection screens (i.e., the three walls) and one downward-projection screen. The fully immersive VR CAVE system enables the combination of motor and cognitive exercises according to a "dual-task" paradigm. Previous studies have reported an association of high immersion and fun while participants were engaging in the VR CAVE experiences $[39,40]$. The application of VR CAVE is able to engage the participants even more than conventional training programs. This is an important factor to consider when designing interactive systems in the medical and rehabilitative field, as greater involvement drives the patients to achieve better results [39]. Taken together, the ability to establish experiences that appear to be more realistic and believable is a major advantage of fully immersive VR systems such as the VR CAVE, which is speculated to engross the participants even more during their game plays and in turn enable them to achieve yet better performances when compared with other forms of training, thereby further enhance their cognitive processes as well as increase the extent to which their mobility could be improved.

Studies have found that VR had some shortcomings, namely simulator disease. Longterm participation in VR may lead to eye fatigue, dizziness, and ataxia [38]. VR may cause participants to hold inappropriate expectations about the outcome, which could result in participants decreasing their participation in non-VR treatments and in turn lead to a decline in their functions [41]. At the same time, VR may also cause patients to pay more attention to performance scores obtained through the process of task completion. They may cheat through some compensatory actions in order to help them achieve higher scores. Patients may start placing competition scores above the original purpose of the training and consciously decide to sacrifice their performance accuracies in order to improve their final completion scores [10]. Although the patients' scores during training had improved under such circumstances, the actual training effect had been reduced. Therefore, VR devices should be designed in ways that could avoid these compensatory actions from happening.

VR and traditional intervention can lead to the same effect on the balance of PD patients, which had important clinical implications. Traditional rehabilitation resources available to each patient were limited and expensive, and long-term treatment may not be possible due to reasons such as travelling inconveniences and other economic concerns. VR can bring about benefits to those patients. Besides, VR can be used as a low-supervised home-based rehabilitation device to help PD patients resume activities at home and in the community. Home-based VR can provide patients with some flexibility and may improve the compliances of those who are easy to give up. Studies have explored the effect of home-based VR for the balance training of PD patients. The studies of Yang, Wang [24] and Gandolfi, Geroin [36] have both showed that home-based VR significantly 
improved participants' balance functions, and that patients can get almost the same effect at home as in the hospital. However, safety is a problem during treatment. Before training, patients need to be trained in the use of the equipment and be briefed on the relevant safety precautions. During the training process, special attention should be paid to the patients. Therapists should maintain regular follow-ups with patients to evaluate their treatment effect. Further research needs to compare the treatment effect under low supervision with that of traditional training.

It is important to use the most relevant assessments during treatment because inappropriate tools may not be able to detect balance disorders sensitively. Studies in this review all chose functional assessments to evaluate balance disorders because these tests were affordable and easy to use, and had been proven as effective in predicting the risk of falls. BBS had high reliability but the sensitivity was poor to moderate [42]. Ceiling effect may mislead the process while assessing patients with mild deficits [43]. Duncan, Leddy [44] also suggested that BBS was not the most appropriate tool to assess balance function in PD, as it cannot detect the difference between patients with or without freezing of gait. TUG may be an accurate tool to identify the risk of falls in PD patients [45]. However, studies found that TUG was sensitive to the treatment in PD but not sensitive when patients were still in the early stages of the disease [46,47]. These subjective assessments had ceiling effects and some symptoms related to balance disorders may not be detected by clinical tests and scales. Therefore, more objective methods should be sought to improve the accuracy of evaluation in clinical practice. The usage of computerized posturography and wearable sensors in objective balance measurement can provide more sensitive and accurate data in clinical assessments. Studies had found that posturography showed a great advantage in detecting fallers in PD patients [48], and wearable inertial sensors could detect balance disorders even before clinical tests found them [49]. TUG, combined with inertial sensors, can detect the dynamic balance impairments in untreated PD patients, although the Get-Up-And-Go time showed no difference [50]. Therefore, it is suggested that physicians should combine subjective scales with objective tools to provide a more accurate and sensitive assessment of balance for their patients in the future.

The research limitations mainly include the following aspects. The sample sizes were limited, which may hinder the generalization of the research results to patients with Parkinson's disease. Differences in the age and gender of the participants, types of VR used, control groups employed, and treatment durations assigned across studies may have led to biases in results. Besides, some studies had no follow-ups while others had follow-up periods that were too short. During the follow-up periods, these studies had imposed no restrictions on the patients' daily activities. The duration of the VR treatment effect is still unclear. Therefore, studies with larger sample sizes should be conducted to better test the effects of VR on the balance functions of patients with PD in future. Future research can design experiments according to different age groups, genders, and disease severities to explore the impact of these factors on PD patients' performances playing with VR. The follow-up period should also be extended in order to determine the duration of the effect of VR on patients with PD.

\section{Conclusions}

This review combines existing evidence on the use of virtual reality technology in the treatment of Parkinson's disease to better study its effect on improving PD patients' balance functions. VR can achieve an equivalent or even a better level of improvement than traditional treatments, and can therefore be used clinically as an auxiliary technology for the treatment of balance functions in patients with Parkinson's disease.

Supplementary Materials: The following are available online at https://www.mdpi.com/article/10 .3390/electronics10091003/s1, Supplementary Material File S1: PRISMA 2020 Checklist; Supplementary Material File S2: Study Quality Assessment. 
Author Contributions: Conceptualization, F.H.-y.L. and W.W.; methodology, F.H.-y.L. and W.W.; software, W.W.; validation, W.W., F.H.-y.L. and S.S.-1.W.; formal analysis, W.W. and F.H.-y.L.; investigation, W.W., F.H.-y.L. and S.S.-1.W.; resources, W.W. and F.H.-y.L.; data curation, W.W. and S.S.-1.W.; writing-original draft preparation, W.W. and F.H.-y.L.; writing-review and editing, W.W., S.S.-1.W. and F.H.-y.L.; visualization, W.W.; supervision, F.H.-y.L.; project administration, F.H.-y.L. and S.S.-1.W.; funding acquisition, F.H.-y.L. All authors have read and agreed to the published version of the manuscript.

Funding: This study was supported by the seed fund scheme arising from the donation of Ir Tam Wing Fan Edmund for setting up Rehabilitation Services Centre (Occupational Therapy) (Primary Work Programme: ZJME).

Informed Consent Statement: Patient consent was waived due to the fact that this is a systematic review involving secondary data synthesized from previous studies. We have not obtained any information from the subjects directly and thus no ethical review was involved.

Data Availability Statement: The following are available online in Supplementary Materials File S1: Preferred Reporting Items for Systematic Reviews and Meta-Analyses (PRISMA) Checklist; Supplementary Materials File S2: Study Quality Assessment.

Conflicts of Interest: The authors declare no conflict of interest.

\section{References}

1. Allen, N.E.; Sherrington, C.; Paul, S.S.; Canning, C.G. Balance and falls in Parkinson's disease: A meta-analysis of the effect of exercise and motor training. Mov. Disord. 2011, 26, 1605-1615. [CrossRef] [PubMed]

2. Sofuwa, O.; Nieuwboer, A.; Desloovere, K.; Willems, A.-M.; Chavret, F.; Jonkers, I. Quantitative Gait Analysis in Parkinson's Disease: Comparison With a Healthy Control Group. Arch. Phys. Med. Rehabil. 2005, 86, 1007-1013. [CrossRef] [PubMed]

3. Abbruzzese, G.; Marchese, R.; Avanzino, L.; Pelosin, E. Rehabilitation for Parkinson's disease: Current outlook and future challenges. Parkinsonism Relat. Disord. 2016, 22, S60-S64. [CrossRef] [PubMed]

4. Vu, T.C.; Nutt, J.G.; Holford, N.H.G. Progression of motor and nonmotor features of Parkinson's disease and their response to treatment. Br. J. Clin. Pharmacol. 2012, 74, 267-283. [CrossRef]

5. Klamroth, S.; Steib, S.; Devan, S.; Pfeifer, K. Effects of exercise therapy on postural instability in Parkinson disease: A meta-analysis. J. Neurol. Phys. Ther. 2016, 40, 3-14. [CrossRef]

6. Hirsch, M.A.; Toole, T.; Maitland, G.G.; Rider, R.A. The effects of balance training and high-intensity resistance training on persons with idiopathic Parkinson's disease. Arch. Phys. Med. Rehabil. 2003, 84, 1109-1117. [CrossRef]

7. Schultheis, M.T.; Rizzo, A.A. The Application of Virtual Reality Technology in Rehabilitation. Rehabil. Psychol. 2001, 46, 296-311. [CrossRef]

8. Ryan, M.-L. Narrative as Virtual Reality 2: Revisiting Immersion and Interactivity in Literature and Electronic Media; JHU Press: Baltimore, MD, USA, 2015; Volume 2.

9. Slater, M.; Linakis, V.; Usoh, M.; Kooper, R. Immersion, presence and performance in virtual environments: An experiment with tri-dimensional chess. In Proceedings of the ACM Symposium on Virtual Reality Software and Technology, Hong Kong, China, 1-4 July 1996.

10. Lewis, G.N.; Rosie, J.A. Virtual reality games for movement rehabilitation in neurological conditions: How do we meet the needs and expectations of the users? Disabil. Rehabil. 2012, 34, 1880-1886. [CrossRef]

11. Mujber, T.; Szecsi, T.; Hashmi, M. Virtual reality applications in manufacturing process simulation. J. Mater. Process. Technol. 2004, 155-156, 1834-1838. [CrossRef]

12. Mirelman, A.; Maidan, I.; Deutsch, J.E. Virtual reality and motor imagery: Promising tools for assessment and therapy in Parkinson's disease. Mov. Disord. 2013, 28, 1597-1608. [CrossRef]

13. Sveistrup, H. Motor rehabilitation using virtual reality. J. Neuroeng. Rehabil. 2004, 1, 10. [CrossRef] [PubMed]

14. Dos Santos Mendes, F.A.; Pompeu, J.E.; Lobo, A.M.; Da Silva, K.G.; Oliveira, T.D.P.; Zomignani, A.P.; Piemonte, M.E.P. Motor learning, retention and transfer after virtual-reality-based training in Parkinson's disease-Effect of motor and cognitive demands of games: A longitudinal, controlled clinical study. Physiotherapy 2012, 98, 217-223. [CrossRef] [PubMed]

15. Joo, L.Y.; Yin, T.S.; Xu, D.; Thia, E.; Fen, C.P.; Kuah, C.; Kong, K. A feasibility study using interactive commercial off-the-shelf computer gaming in upper limb rehabilitation in patients after stroke. J. Rehabil. Med. 2010, 42, 437-441.

16. Studenski, S. Gait Speed and Survival in Older Adults. JAMA 2011, 305, 50-58. [CrossRef] [PubMed]

17. Wang, B.; Shen, M.; Wang, Y.-X.; He, Z.-W.; Chi, S.-Q.; Yang, Z.-H. Effect of virtual reality on balance and gait ability in patients with Parkinson's disease: A systematic review and meta-analysis. Clin. Rehabil. 2019, 33, 1130-1138. [CrossRef]

18. Lei, C.; Sunzi, K.; Dai, F.; Liu, X.; Wang, Y.; Zhang, B.; He, L.; Ju, M. Effects of virtual reality rehabilitation training on gait and balance in patients with Parkinson's disease: A systematic review. PLoS ONE 2019, 14, e0224819. [CrossRef]

19. Weiss, P.L.T.; Katz, N. The potential of virtual reality for rehabilitation. J. Rehabil. Res. Dev. 2004, 41, 7-10. 
20. Riva, G.; Mantovani, F.; Gaggioli, A. Presence and rehabilitation: Toward second-generation virtual reality applications in neuropsychology. J. Neuroeng. Rehabil. 2004, 1, 9. [CrossRef]

21. Schoneburg, B.; Mancini, M.; Horak, F.; Nutt, J.G. Framework for understanding balance dysfunction in Parkinson's disease. Mov. Disord. 2013, 28, 1474-1482. [CrossRef]

22. Higgins, J.P.T.; Thomas, J.; Chandler, J.; Cumpston, M.; Li, T.; Page, M.J.; Welch, V.A. Cochrane Handbook for Systematic Reviews of Interventions Version 6.2; Updated February 2021; Cochrane: Chichester, UK, 2021.

23. Yen, C.-Y.; Lin, K.-H.; Hu, M.-H.; Wu, R.-M.; Lu, T.-W.; Lin, C.-H. Effects of Virtual Reality-Augmented Balance Training on Sensory Organization and Attentional Demand for Postural Control in People With Parkinson Disease: A Randomized Controlled Trial. Phys. Ther. 2011, 91, 862-874. [CrossRef]

24. Yang, W.-C.; Wang, H.-K.; Wu, R.-M.; Lo, C.-S.; Lin, K.-H. Home-based virtual reality balance training and conventional balance training in Parkinson's disease: A randomized controlled trial. J. Formos. Med Assoc. 2016, 115, 734-743. [CrossRef]

25. Van den Heuvel, M.R.C.; Kwakkel, G.; Beek, P.J.; Berendse, H.W.; Daffertshofer, A.; van Wegen, E.E. Effects of augmented visual feedback during balance training in Parkinson's disease: A pilot randomized clinical trial. Park. Relat. Disord. 2014, 20, 1352-1358. [CrossRef] [PubMed]

26. Tollár, J.; Nagy, F.; Hortobágyi, T. Vastly Different Exercise Programs Similarly Improve Parkinsonian Symptoms: A Randomized Clinical Trial. Gerontology 2019, 65, 120-127. [CrossRef] [PubMed]

27. Shih, M.-C.; Wang, R.-Y.; Cheng, S.-J.; Yang, Y.-R. Effects of a balance-based exergaming intervention using the Kinect sensor on posture stability in individuals with Parkinson's disease: A single-blinded randomized controlled trial. J. Neuroeng. Rehabil. 2016, 13, 1-9. [CrossRef]

28. Santos, P.; Machado, T.; Santos, L.; Ribeiro, N.; Melo, A. Efficacy of the Nintendo Wii combination with Conventional Exercises in the rehabilitation of individuals with Parkinson's disease: A randomized clinical trial. Neurorehabilitation 2019, 45, 255-263. [CrossRef] [PubMed]

29. Ribas, C.G.; da Silva, L.A.; Corrêa, M.R.; Teive, H.G.; Valderramas, S. Effectiveness of exergaming in improving functional balance, fatigue and quality of life in Parkinson's disease: A pilot randomized controlled trial. Park. Relat. Disord. 2017, 38, 13-18. [CrossRef]

30. Pompeu, J.E.; Mendes, F.A.D.S.; Da Silva, K.G.; Lobo, A.M.; Oliveira, T.D.P.; Zomignani, A.P.; Piemonte, M.E.P. Effect of Nintendo Wii ${ }^{\mathrm{TM}}$-based motor and cognitive training on activities of daily living in patients with Parkinson's disease: A randomised clinical trial. Physiotherapy 2012, 98, 196-204. [CrossRef] [PubMed]

31. Pedreira, G.; Prazeres, A.; Cruz, D.; Gomes, I.; Monteiro, L.; Melo, A. Virtual games and quality of life in Parkinson's disease: A randomised controlled trial. Adv. Park. Dis. 2013, 2, 97-101. [CrossRef]

32. Pazzaglia, C.; Imbimbo, I.; Tranchita, E.; Minganti, C.; Ricciardi, D.; Monaco, R.L.; Parisi, A.; Padua, L. Comparison of virtual reality rehabilitation and conventional rehabilitation in Parkinson's disease: A randomised controlled trial. Physiotherapy 2020, 106, 36-42. [CrossRef]

33. Liao, Y.-Y.; Yang, Y.-R.; Wu, Y.-R.; Wang, R.-Y. Virtual Reality-Based Wii Fit Training in Improving Muscle Strength, Sensory Integration Ability, and Walking Abilities in Patients with Parkinson's Disease: A Randomized Control Trial. Int. J. Gerontol. 2015, 9, 190-195. [CrossRef]

34. Liao, Y.-Y.; Yang, Y.-R.; Cheng, S.-J.; Wu, Y.-R.; Fuh, J.-L.; Wang, R.-Y. Virtual Reality-Based Training to Improve ObstacleCrossing Performance and Dynamic Balance in Patients With Parkinson's Disease. Neurorehabilit. Neural Repair 2014, 29, 658-667. [CrossRef] [PubMed]

35. Lee, N.-Y.; Lee, D.-K.; Song, H.-S. Effect of virtual reality dance exercise on the balance, activities of daily living, and depressive disorder status of Parkinson's disease patients. J. Phys. Ther. Sci. 2015, 27, 145-147. [CrossRef]

36. Gandolfi, M.; Geroin, C.; Dimitrova, E.; Boldrini, P.; Waldner, A.; Bonadiman, S.; Picelli, A.; Regazzo, S.; Stirbu, E.; Primon, D.; et al. Virtual Reality Telerehabilitation for Postural Instability in Parkinson's Disease: A Multicenter, Single-Blind, Randomized, Controlled Trial. BioMed Res. Int. 2017, 2017, 1-11. [CrossRef] [PubMed]

37. Feng, H.; Li, C.; Liu, J.; Wang, L.; Ma, J.; Li, G.; Gan, L.; Shang, X.; Wu, Z. Virtual Reality Rehabilitation Versus Conventional Physical Therapy for Improving Balance and Gait in Parkinson's Disease Patients: A Randomized Controlled Trial. Med. Sci. Monit. 2019, 25, 4186-4192. [CrossRef]

38. Rose, T.; Nam, C.S.; Chen, K.B. Immersion of virtual reality for rehabilitation-Review. Appl. Ergon. 2018, 69, 153-161. [CrossRef] [PubMed]

39. Zimmerli, L.; Jacky, M.; Lünenburger, L.; Riener, R.; Bolliger, M. Increasing Patient Engagement During Virtual Reality-Based Motor Rehabilitation. Arch. Phys. Med. Rehabil. 2013, 94, 1737-1746. [CrossRef]

40. Mirelman, A.; Rochester, L.; Maidan, I.; Del Din, S.; Alcock, L.; Nieuwhof, F.; Rikkert, M.O.; Bloem, B.R.; Pelosin, E.; Avanzino, L.; et al. Addition of a non-immersive virtual reality component to treadmill training to reduce fall risk in older adults (V-TIME): A randomised controlled trial. Lancet 2016, 388, 1170-1182. [CrossRef]

41. Lewis, G.N.; Woods, C.; Rosie, J.A.; McPherson, K.M. Virtual reality games for rehabilitation of people with stroke: Perspectives from the users. Disabil. Rehabil. Assist. Technol. 2010, 6, 453-463. [CrossRef]

42. Berg, K.; Wood-Dauphinee, S.; Williams, J.I. The Balance Scale: Reliability assessment with elderly residents and patients with an acute stroke. Scand. J. Rehabil. Med. 1995, 27, 27-36. 
43. Schlenstedt, C.; Brombacher, S.; Hartwigsen, G.; Weisser, B.; Möller, B.; Deuschl, G. Comparison of the Fullerton Advanced Balance Scale, Mini-BESTest, and Berg Balance Scale to Predict Falls in Parkinson Disease. Phys. Ther. 2016, 96, 494-501. [CrossRef] [PubMed]

44. Duncan, R.P.; Leddy, A.L.; Cavanaugh, J.T.; Dibble, L.E.; Ellis, T.D.; Ford, M.P.; Foreman, K.B.; Earhart, G.M. Balance differences in people with Parkinson disease with and without freezing of gait. Gait Posture 2015, 42, 306-309. [CrossRef] [PubMed]

45. Nocera, J.R.; Stegemöller, E.L.; Malaty, I.A.; Okun, M.S.; Marsiske, M.; Hass, C.J. Using the Timed Up \& Go Test in a Clinical Setting to Predict Falling in Parkinson's Disease. Arch. Phys. Med. Rehabil. 2013, 94, 1300-1305. [PubMed]

46. Zampieri, C.; Salarian, A.; Carlson-Kuhta, P.; Aminian, K.; Nutt, J.G.; Horak, F.B. An instrumented timed up and go test characterizes gait and postural transitions in untreated Parkinson's disease. J. Neurol. Neurosurg. Psychiatry 2009. [CrossRef]

47. Auriel, E.; Hausdorff, J.; Talia, H.; Simon, E.S.; Giladi, N. Effects of methylphenidate on cognitive function and gait in patients with Parkinson's disease: A pilot study. Clin. Neuropharmacol. 2006, 29, 15-17. [CrossRef] [PubMed]

48. Rossi-Izquierdo, M.; Basta, D.; Rubio-Rodríguez, J.P.; Santos-Pérez, S.; Ernst, A.; Sesar-Ignacio, A.; Alberte-Woodward, M.; Amo, M.G.-D.; Estany-Gestal, A.; Román-Rodríguez, E.S.; et al. Is posturography able to identify fallers in patients with Parkinson's disease? Gait Posture 2014, 40, 53-57. [CrossRef]

49. Mancini, M.; Horak, F.B. The relevance of clinical balance assessment tools to differentiate balance deficits. Eur. J. Phys. Rehabil. Med. 2010, 46, 239-248. [PubMed]

50. Salarian, A.; Zampieri, C.; Horak, F.B.; Carlson-Kuhta, P.; Nutt, J.G.; Aminian, K. Analyzing $180^{\circ}$ turns using an inertial system reveals early signs of progression of parkinson's disease. In Proceedings of the 2009 Annual International Conference of the IEEE Engineering in Medicine and Biology Society, Minneapolis, MS, USA, 3-6 September 2009; Institute of Electrical and Electronics Engineers (IEEE): Minneapolis, MS, USA, 2009; Volume 2009, pp. 224-227. 